\title{
La poética teatral de Omar Serra en la versión de un texto de Sade. Una puesta que irrumpe en la escena rosarina
}

Daniela Silvia Ponte

Universidad Nacional de Rosario, Argentina

dasponte@hotmail.com

Fecha de recepción: 27/03/2021. Fecha de aceptación: 16/04/2021

\begin{abstract}
Resumen
Sobreviviente de los “60 (Serra: 1997) y portador de la estética y del "modo de los '80" (Lucena y Laboureau, 2016:16), Omar Serra estrena en abril del 2017 en Rosario Filosofía en el Tocador, una adaptación original de la novela homónima escrita por Donatien Alphonse François de Sade -conocido como el Marqués de Sade-y publicada en 1795. Un cuidado vestuario de época, música de Queen, escenas al filo del sexo explícito, centralidad y protagonismo de lo corporal, son algunos de los elementos que se ponen en juego para evocar a la corte francesa de finales del siglo XVIII y constituyen el marco en el que Serra nos enseña nuevamente como llevar la impronta del under a la escena rosarina. En el presente trabajo exploraremos las particularidades de la poética serreana presentes en una puesta tan intensa como perturbadora.
\end{abstract}

Palabas clave: Serra, Marqués de Sade, teatro de posdictadura, teatro rosarino, dramaturgia

\section{The Theatrical Poetics of Omar Serra in the Version of a Text by Sade. A Staging that Bursts into the Rosario Scene}

\begin{abstract}
A survivor of the "6os (Serra: 1997) and bearer of the aesthetics and the "8os mode" (Lucena and Laboureau, 2016: 16), Omar Serra presents in April 2017 in Rosario Filosofia en el Tocador, an original adaptation of the homonymous novel written by Donatien Alphonse François de Sade -known as the Marquis de Sade- and published in 1795 .

A careful period wardrobe, music by Queen, scenes on the edge of explicit sex, centrality and prominence of the body, are some of the elements that are put into play to evoke the French court of the late 18th century and constitute the framework in which Serra shows us once again how to bring the imprint of under to the Rosario scene.
\end{abstract}


In the present work we will explore the particularities of Serrean poetics present in a play that is as intense as it is disturbing.

Keywords: Serra, Marquis de Sade, post-dictatorship theater, Rosario theater, dramaturgy

Precisamente a mí no me gustan las definiciones, pero si alguien me pregunta qué tipo de teatro hago yo, siempre digo: Teatro erótico, herético y poético. (Serra, 2002: 12)

\section{Introducción}

Omar Serra es actor, director y dramaturgo. Nació en Rosario el 9 de marzo de 1946. De pequeño se traslada a Buenos Aires hasta 1978. Luego, retorna a Rosario, donde aún reside. En anteriores trabajos sobre Serra (Ponte, 2016:268), hemos establecido tres hitos fundantes de su hacer artístico: en primer lugar, su participación en el movimiento hippie durante la década del 60 (narrada en detalles en Generación Descartable, texto autobiográfico inédito), vivencia que comparte junto a Miguel Abuelo, Tanguito, Pipo Lernoud y Fernando Noy. En segundo lugar, debemos mencionar sus inicios en el teatro durante la década del 80, formando parte del movimiento under porteño, junto a Batato Barea y Alejandro Urdapilleta, experiencia compartida también con Noy, su amigo personal, con quien aún mantiene un vínculo fluido. El tercer momento significativo en el trayecto artístico personal de Serra se da entre el 94 y el 95, cuando crea en Rosario la Compañía Sabina Beher, con la que puso en escena puestas emblemáticas como La Voz Humana de Jean Cocteau; La Condesa Sangrienta, sobre textos de Alejandra Pizarnik y Valentine Penrouse; Los pájaros del Deseo, versión teatral del caso del juez Schreber; Eva Perón de Copi y Layo de Sófocles, entre otras. Pero en la rica y prolífica producción de Serra ha llegado el momento de agregar un nuevo hito: la puesta en escena de Filosofía en el Tocador, adaptación teatral de la novela del Marqués de Sade que se estrenó bajo su dirección en la ciudad de Rosario en abril de 2017.

Dice Foucault "El poder no se construye a partir de voluntades (individuales o colectivas), ni tampoco se deriva de intereses. El poder se construye y funciona a partir de poderes, de multitud de cuestiones y de efectos de poder." (1979:157). Es por eso que, según el autor, sería más preciso posar la mirada no en el poder que se presenta y se ejerce desde el Estado, sino en las relaciones de poder que se reproducen en la vida cotidiana, en el modo en que este poder se ejerce a través de las relaciones vinculares. Siguiendo a Foucault, diremos además que “(...) no existen relaciones de poder sin resistencia (...) que la resistencia surge allí mismo, donde se dan las relaciones de poder" (1979: 71). 


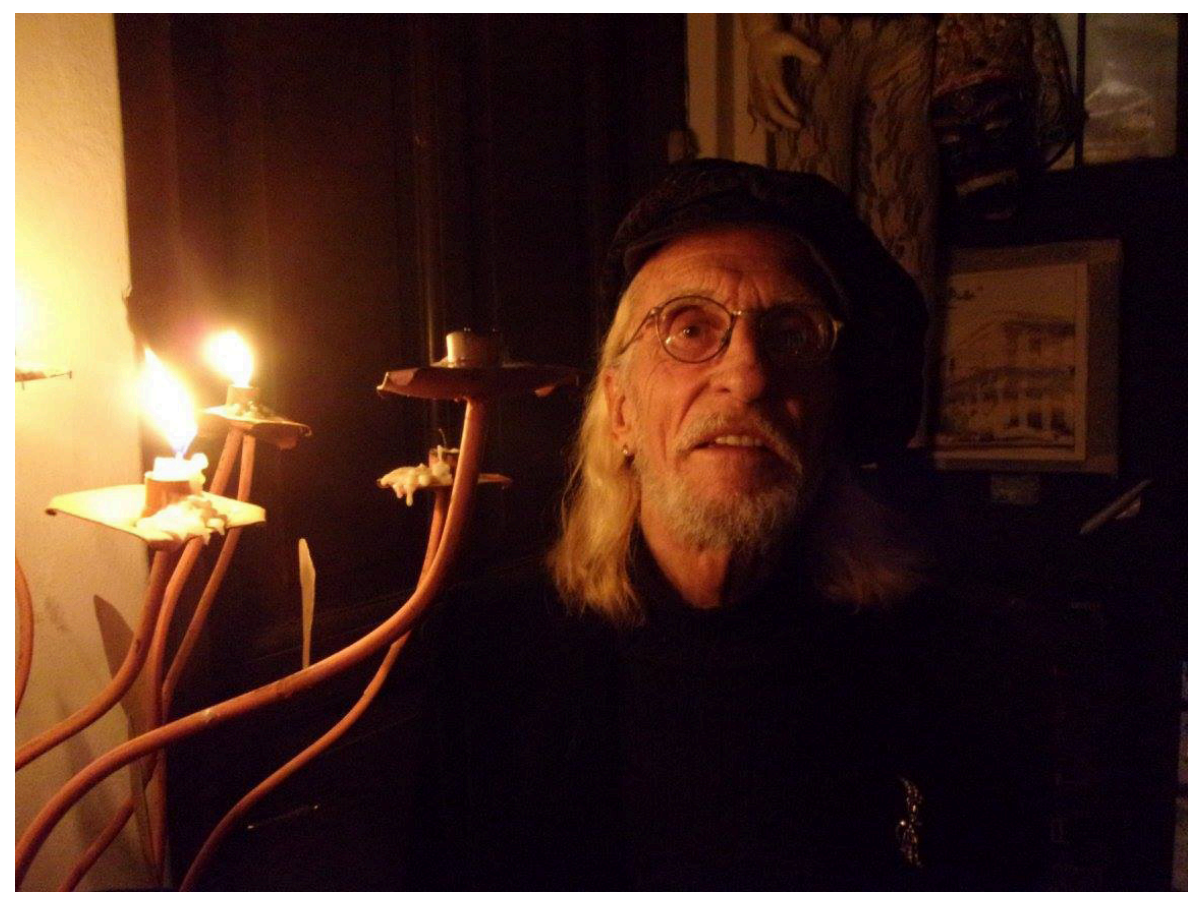

Foto: Autorretrato de Omar Serra

Si pensamos el poder en términos de negación, de prohibición, de cercenamiento de libertades, sería posible establecer cierta analogía entre las relaciones poder- resistencia/prohibición-transgresión. En tal sentido, George Bataille (1988) sostiene:

Sade expuso la doctrina de la irregularidad de tal modo, mezclada con tales horrores, que nadie se percató de ello. Quería subleva la conciencia, hubiera querido también esclarecerla, pero no pudo a un tiempo sublevarla y esclarecerla. Sólo hoy entendemos que, sin la crueldad de Sade, no hubiéramos alcanzado tan fácilmente este campo antaño inaccesible donde se disimulaban las más penosas verdades. Y si hoy el hombre normal penetra profundamente en la conciencia de lo que significa, para él, la transgresión, es porque Sade preparó el camino. Ahora el hombre normal sabe que su conciencia tenía que abrirse a lo que más violentamente lo había sublevado: lo que más violentamente nos subleva, está dentro de nosotros. (Bataille, 1988: 146)

La preferencia de Serra por autores marginales, malditos o poco representados, fue una constante en todas sus producciones. Si bien en su puesta de La Condesa Sangrienta (Rosario, 2000) se incorporaron algunos textos de Sade, es la primera vez que aborda una obra entera de este autor admirado y referenciado tanto en entrevistas como en el dictado de sus talleres de actuación. "Nos encanta trabajar con los escritores malditos -Becket, Pizarnik, Rimbaud, Baudelaire, Perlongher, Sade, Loutremont- porque en esa tendencia hay todo un enfrentamiento con la sociedad. Son malditos, porque son los que reflejan una sociedad que está tapada y es inquietante, ¿no?" (Serra, 2001:16)

Esta preferencia, que constituye un rasgo fundamental de su poética, esta voluntad de abordar lo inquietante, trajo aparejada durante mucho tiempo la idea de que el público que se acercaba a ver estas obras debía estar, al menos, advertido. "Estamos convencidos de que trabajamos para cierto público elitista, aunque suene una barbaridad. Sabemos que lo que hacemos no puede llegar a todo el mundo," (Serra, 2000: 18). En relación a este tema, en otra entrevista agrega: "Yo diría que el público que 
nos aborda tiene que tener una inquietud. Tiene que llevar al teatro algún malestar en la cultura. Tiene que dejar brotar. No nos interesa captar otro". (Serra, 2002: 12). '

\section{Filosofía en el Tocador}

Desde su estreno y hasta finales del 2019, Filosofía en el Tocador se ha presentado cada sábado a sala llena y el flujo de público parece no cesar. La temporada 2020 estaba en preparación cuando fue interrumpida por la pandemia de Covid-19. Este fenómeno, estimulado por el boca en boca ha llamado la atención del periodismo especializado de la ciudad, quienes no solamente le han dado un espacio en sus publicaciones, sino que además coinciden -desde perspectivas diferentes- en que se trata de una puesta muy lograda, elogiando tanto la adaptación, la dirección, el vestuario, la música, la escenografía y las actuaciones.

Hay un punto de coincidencia entre todos los comentarios y críticas que esta puesta ha recibido: el carácter perturbador y profundamente provocador que atraviesa la puesta y que va in crescendo desde el principio hasta el final. A estas consideraciones es preciso ponerlas en contexto.

Podemos comenzar por afirmar que el abordaje de esta obra no fue un trabajo sencillo ni lineal. Demandó dos años de preparación, puesto que la adaptación de novela a texto dramático fue realizada por el grupo de actores, bajo la supervisión del director. Este trabajo incluyó lecturas de varias traducciones del original y un estudio minucioso sobre el autor y su época. Vale agregar que no es la primera vez que un elenco dirigido por Serra abona este modo de producción. Por el contrario, parece ser una marca presente en todas las puestas de la Compañia Sabina Beher, aunque, en este caso, los actores eligieron llamarse Gupo Klan Destino.

En la adaptación dramatúrgica. los personajes enuncian de manera casi literal los parlamentos propuestos por Sade, pero se advierten ciertas licencias que nos recuerdan que la mixtura de textos y de géneros es otra constante en las producciones de la Sabina Beher. La poesía de Pizarnik, Rimbaud y Verlaine se filtran entre los textos del Marqués. Este gusto por incluir la poesía en las puestas nos remite al concepto de performance poética desarrollado por Irina Garbatzky (2013) en Los ochenta recienvivos.

Si bien se trata de una obra cuya estructura dramática responde a cierta linealidad argumental, la misma presenta rupturas que vale la pena mencionar. Al brevísimo fragmento de Rapsodia Bohemia de Queen, que suena en varias ocasiones interrumpiendo el diálogo entre Madame Saint-Ange y la joven Eugenia, se suma el momento en que ellas junto a Monsieur Dolmancé bailan al son de I want to break free-también de Queen- mientras sostienen en sus manos vasos con bebidas alcohólicas. Acompaña la escena un juego de luces de colores intermitentes: la habitación se convierte en discoteca y la seducción que ejercen Saint-Ange y Dolmancé sobre Eugenia anuncian el desenfreno que está a punto de desatarse entre ellos.

Pero el quiebre más serreano de la puesta es el que protagoniza Madame de Mistival. Su ingreso a la escena -con intenciones de evitar que su hija Eugenia sea iniciada en los placeres sexuales por Madame Saint-Ange y Monsieur Dolmancé- constituye una performance en sí misma. Con un atuendo totalmente negro, capa y capucha del mismo color sobre la que coloca un tocado de monja blanco, Madame de Mistival irrumpe por entre el público cantando y bailando al son de Quiero ser santa, un hit del grupo de punk rock gótico madrileño Parálisis Permanente en la voz de Alaska, de principio de los 80 . Así, el espectador asiste y es invitado a ser parte de la iniciación sexual de una joven de quince años por parte de un grupo de libertinos 
miembros de la nobleza, mientras afuera la Revolución Francesa hace tambalear los privilegios y la impunidad sobre los que construyeron su existencia.

Ni Omar Serra, ni su grupo, ni el espacio en el que se presenta su obra han recibido nunca ningún subsidio. La sala Alfred Jarry, que además es su vivienda personal, es una casa antigua, ubicada en el centro de Rosario, en cuya habitación principal cada sábado alrededor de la medianoche el grupo Klan Destino ofrece su puesta de Filosofía en el Tocador. Puesto que el sitio no pertenece al circuito oficial, ni del INT, ni de ninguna otra organización, se accede al mismo sólo con reservas previas y mediante contacto telefónico o vía Facebook.

El público entra por un pasillo y galería de arte e ingresa luego a un patio cuya decoración -realizada por el dueño de casa- encuadra dentro de lo ecléctico. Afiches de teatro y de cine, esculturas, objetos intervenidos, fuente de agua, plantas y un mural circular que representa a Agave, una bacante griega (realizado por él mismo), entre otras. Todos los objetos parecieran haber sido rescatados de algún lugar.

Mientras se espera para ingresar a la sala, Serra fotografía a cada uno de los espectadores, (fotos que son compartidas luego en sus redes sociales). El espectáculo ya ha comenzado. En la sala, una gran cama, un tocador y varios objetos ocupan el espacio escénico. El espectador podrá elegir sentarse en algún sillón, en sillas de diferentes tipos, en almohadones o en una pequeña grada de madera. El director se ubica en un sillón tan cerca de la escena que parece mezclarse con ella.

En cuanto al vestuario, podríamos decir que es una recreación de la moda de la época. Los diseños están inspirados en modelos reales, pero con lugar para algunas licencias, especialmente en la falda que luce Madame Saint-Ange.

Al finalizar la obra, Omar Serra toma el espacio escénico portando un montón de papeles cortados y un tubo de metal. Cuenta que el Marqués, mientras estaba preso en la Bastilla, arengaba a la revolución gritando desde su celda a través del tubo por el que circulaban los desechos sanitarios. Recrea la acción y concluye tirando papeles al aire. De esta manera los espectadores asisten a la performance final.

La puesta en escena de cuerpos que desafían lo heteronorma es otro fuerte rasgo característico de la poética de Serra y que, particularmente en esta obra, cobra significativa relevancia. Es así que el personaje de Eugenia, vestido con una malla del color de su piel adherida a su cuerpo, exhibe con voluptuosidad toda su femineidad transgénero. Esto corresponde la segunda temporada, ya que, durante la primera y la tercera, el personaje fue interpretado por una actriz/mujer cis. En sintonía, pero haciendo alarde de su pacatería, algo similar sucede con el personaje de Madame de Mistival. En tanto que el personaje de Madame Saint-Ange está a cargo de un actor que se trasviste para poner en juego su interpretación. Este actor interpretó el personaje durante las dos primeras temporadas, mientras que en la tercera este rol fue interpretado por una actriz/mujer cis.

Dice Serra: "El cuerpo, la desnudez y el erotismo son los elementos más vitales que tenemos, donde no nos podemos equivocar. Se puede mentir con muchas cosas, pero con el cuerpo no. El cuerpo no miente" (Serra, 2002:12).

Entonces, promediando la función, una pantalla para proyectar cine irrumpe en la recámara de Madame Saint-Ange. Y entre la oscuridad total, los espectadores - ¿sorprendidos?, ¿entusiasmados?, ¿perturbados? - asisten a la proyección de un cortometraje (realizado por Elder Soares, actor que interpreta al Caballero de Mirvel) que reúne escenas pornográficas de procedencia variada, junto a escenas de rebeliones 
populares, ejércitos y guerras. Americano interpretado por Lady Gaga es el tema elegido para esta intervención audiovisual, cuyo impacto en la puesta y en los espectadores merece un tratamiento que excede el presente trabajo y que refuerza y reafirma el tono erótico que sobrevuela en la escena desde el inicio de la puesta.

\section{Camp}

Además de los objetos escénicos, del vestuario, maquillaje y accesorios, las interpretaciones de Madame Saint-Ange, Monsieur Dolmancé y Eugenia le dan a esta puesta el toque camp que Serra aborda casi intuitivamente. El resto de los personajes El Caballero de Mirvel, Madame de Mistival y George Lapierre (que en la tercera temporada este personaje es interpretado por el propio Serra) acompañan y se ajustan a este estilo.

En Notas sobre lo Camp, Susan Sontag (1964) afirma que el camp es ante todo una sensibilidad, una forma de esteticismo, una manera de mirar el mundo como fenómeno estético en la que el estilo está por sobre el contenido. Esta sensibilidad se sostiene en la preferencia por lo no natural, lo artificial, lo exagerado, lo extravagante. Dentro de este canon, el ser es la representación de un papel, es por ello que puede describirse como la más alta expresión de la metáfora de la vida como teatro.

Por su parte, José Amícola en Campy Posvanguardia (2000), hace referencia a lo camp como artificio, como exacerbación de la actuación, pero introduce además la discusión en torno a la identidad de género. Para referirnos a este rasgo de estilo que caracteriza a la poética teatral de Serra, sostendremos el punto de vista de Judith Butler (2007), quien postula el rechazo a todo intento de regular la identidad y sostiene que la sexualidad no se resume fácilmente ni se unifica a través de categorizaciones. Por lo tanto, "el género no es el resultado causal del sexo ni tampoco es tan aparentemente rígido como el sexo". (Butler, 2007:22). Llevada hasta su límite lógico, la distinción sexo-género muestra una discontinuidad radical entre cuerpos sexuados y géneros culturalmente construidos. Butler planteará al género como un artificio ambiguo. En este sentido, los cuerpos o las superficies corporales (Butler, 2007) vendrían a representar el espacio natural posible de convertirse en sitio de actuación disonante y desnaturalizada que otorgaría al género la categoría de performático, es decir, que se da como conducta restaurada, repetida y aprendida socialmente. En tal sentido, y por todo lo hasta aquí expuesto, Filosofía en el Tocador continúa, renueva y mantiene vigente la impronta underground sostenida por el teatro de posdictadura del que Serra fue -cómo ya hemos mencionado- hacedor y protagonista.

\section{El modo de los 80}

Dice Dubatti, respecto de aquellas manifestaciones de las artes escénicas que surgieron-especialmente en la ciudad de Buenos Aires- en el inicio de la década del 80, cuando el horror del Terrorismo de Estado plasmaba su huella indeleble en la historia: "El nuevo teatro puede definirse por la fundación de una poética diversa, polimórfica, que incluye diferentes posibilidades discursivas, no una cristalización estricta y rígida de rasgos, sino modelos en variación de distintas líneas internas." (1995: 28)

En 2016, Daniela Lucena y Gisela Laboureau publican Modo mata Moda. La frase que da título a este libro surge de la entrevista al músico Daniel Melero, quien expresó: "A mí me parece que el modo mata moda (...) de eso estoy seguro" (en Lucena y Laboureau, 2016:82). Esta afirmación se refiere “(...) a un estilo que en su originalidad y singularidad logra perdurar más allá de la moda, constitutivamente efímera, cambiante y pasajera" (43). A partir de esta idea, las autoras trazan una serie de 
características propias de este modo particular de abordar las artes escénicas y determinan la existencia de cuatro estéticas: "colaboración, precariedad, contra-estética vestimentaria y fiesta" (43).

Este movimiento surgido en Buenos Aires encuentra allí innumerables referentes. Cada uno creador de algo que lo destaca. Sin embargo, en Rosario, es Omar Serra quién ha logrado mantener y hacer perdurable esta estética y ser productor de esta poética única. (Ponte: 2016). Y quizás sea así porque La Compañía Sabina Beher profesa una estética y una ética propias alejadas de las modas circunstanciales y hace de ellas no sólo una forma de hacer arte, sino una forma de vida.

Según Bourdieu (2002:31), existe una relación de transitividad entre el creador y su obra según el lugar de pertenencia de éste. En tal sentido, diferencia al artista cuyas obras circulan en circuitos oficiales del artista marginal. Sostiene además que este último, una vez definido como tal, mantiene su lugar en tanto y en cuanto no se deje tentar por su "nostalgia de integración a la institución oficial" (2002:31). Al respecto, Serra afirma en una entrevista inédita realizada por el poeta Miguel Erre: "Cuando uno entra en el circuito profesional tiene que pasar por Buenos Aires; a mí nunca me interesó ese tipo de circuito comercial. Siempre fui un creador underground y un vanguardista y la vanguardia... no está apoyada por nada, al contrario, más bien es combatida que apoyada." (Serra, 2010). Y es que, como expresa Fernando Noy en la contratapa de Historias del under, "los artistas del under no se han extinguido: el árbol sigue plantando, aún vecino a la maleza transgénica anticreativa."

\section{El modo Serra}

Hemos mencionado en el inicio del presente trabajo algunas de las producciones anteriores de Serra que también llevan la impronta de su hacer. Nos referiremos a algunas de ellas. En 1996, estrena la primera producción de la Compañía Sabina Beher: La Voz Humana, de Jean Cocteau, protagonizada por el propio Serra (Ponte: 2017). Aquí irrumpe en escena Omar Serra montado sobre coturnos y con un vestuario entre punk y trash interpretando el monólogo de Cocteau. La Condesa Sangrienta, estrenada en el 2000, sobre textos de Alejandra Pizarnik y Valentine Penrouse, es un trabajo de adaptación dramatúrgica en el que combina el ensayo histórico de Penrouse -a partir del cual se estructura la trama de la puesta-, con la poesía de Pizarnik poniendo voz a los personajes (Ponte: 2015). A esta puesta le siguen La Bucanera de Pernambuco y Poseidos entre Lilas, ambas de Pizarnik, en lo que Omar Serra menciona como La trilogía Pizarnik llevada a escena por la Compañía.

En 2001, estrena Eva Perón de Copi (Ponte: 2016), un hito del teatro camp. Esta obra es una de las pocas en las que Serra y su elenco se ajustan a un texto dramático en vitro, tal como lo indica el autor, con excepción de la inclusión de un fragmento del poema El cadáver de la nación de Néstor Perlongher recitado por el personaje de Eva, que es interpretado por el propio Serra.

$\mathrm{Al}$ año siguiente, llega el turno de Los pájaros del deseo, una puesta que recrea la vida y la obra del juez Daniel Schereber. En este caso se realizó una adaptación dramatúrgica tomando como base el texto Memorias de un enfermo nervioso, del propio Schreber, junto a una minuciosa investigación sobre otros textos que abordan este tema, incluido el de Sigmund Freud.

Párrafo aparte merece la puesta de Layo de Sófocles (Ponte: 2017), en la que Serra se aventura a reescribir una tragedia griega a partir de los restos encontrados de diversos textos de Sófocles. Esta puesta en escena, que demandó varios años de investigación 
y de un trabajo dramatúrgico grupal, fue estrenada en 2013 y representa, según el propio Serra, su obra más lograda.

En Concepciones de Teatro, Dubatti resalta la necesidad de historizar las poéticas teatrales:

Llamamos historicidad al principio de necesidad histórica por el que: a) una poética teatral corresponde a un tiempo determinado y a la inserción de ese tiempo en una territorialidad particular en cuanto a sus condiciones de posibilidad, b) no podría haber surgido en otro momento histórico." (2009: 8)

Diciembre de 2015 es una fecha que indica un cambio de época en nuestro país en consonancia con América Latina y el resto del mundo. Comienza aquí un período -que en Argentina se extenderá hasta diciembre del 2019-, en el que, como menciona Lorena Verzero en el prólogo del libro de Lucena y Lauboreau “(...) que recupera una matriz conservadora tributaria de formas hegemónicas heredadas de la modernidad" (2016:15).

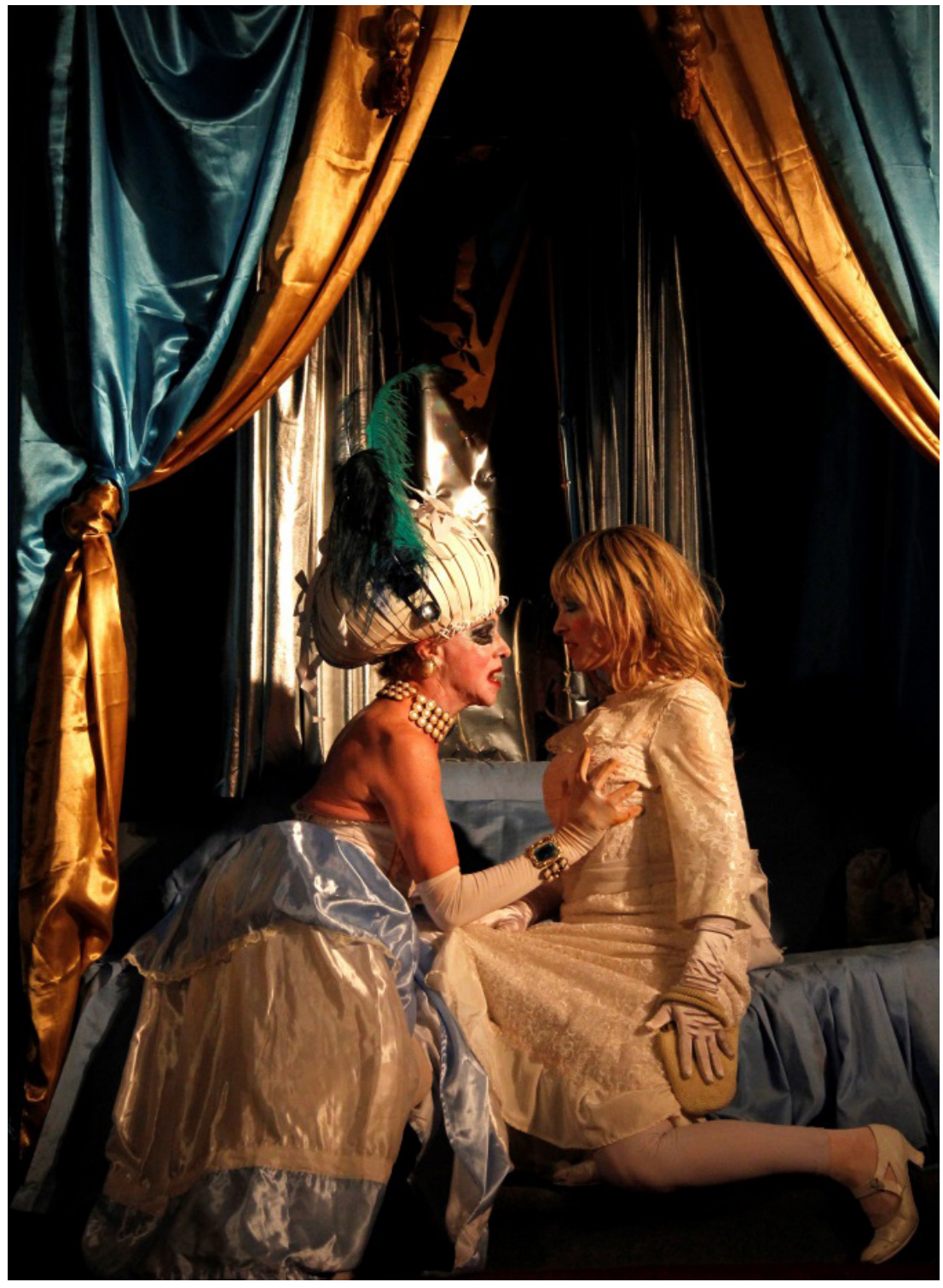

Madame Saint-Ange y Eugenia. Escena de Filosofía en el Tocador. Foto: Omar Serra 


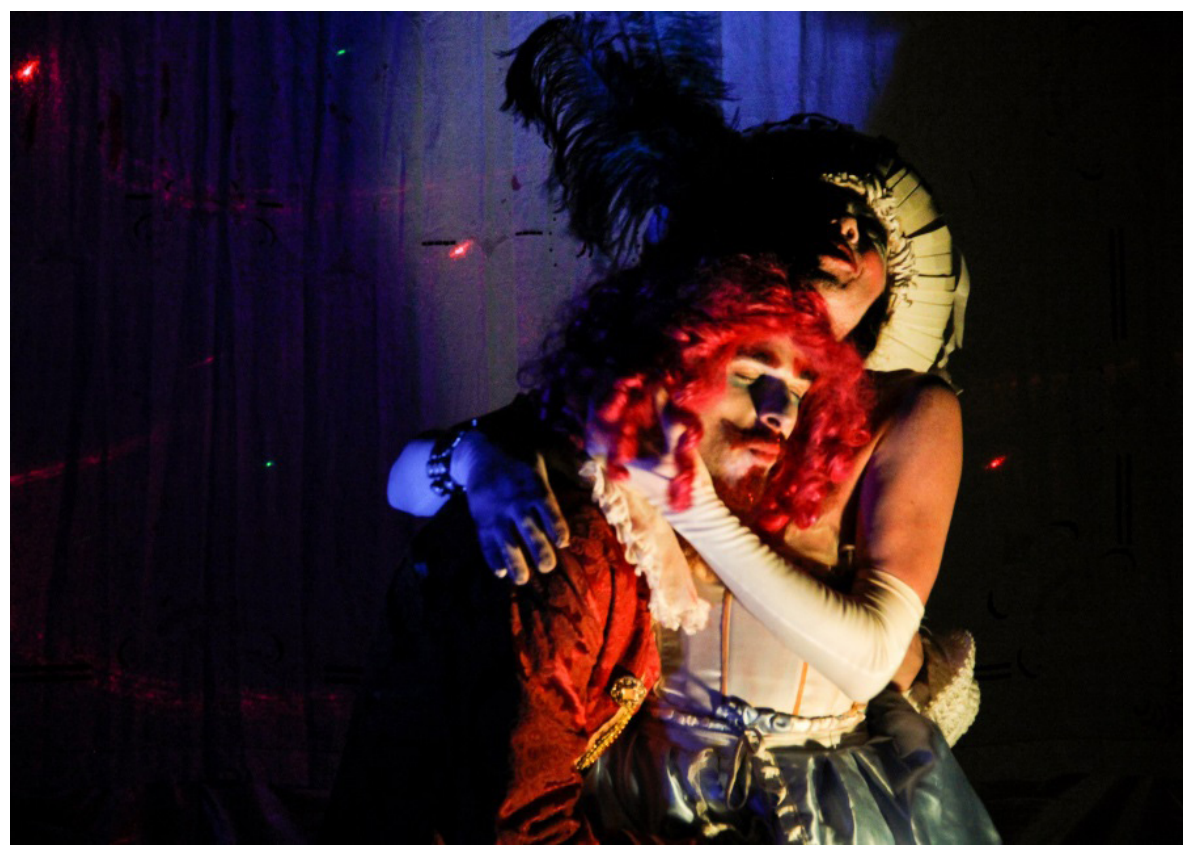

Caballero de Mirvel y Madame Saint Ange. Escena de Filosofía en el Tocador. Foto: Omar Serra

En este punto volvemos a las citas de Foucault y Bataille mencionadas en el inicio del presente trabajo. La puesta en escena de Filosofía en el Tocador pone en evidencia que todo acto de poder genera resistencias y que la escritura y el pensamiento de Sade resultan imprescindibles para comprender las posibilidades de transgresión del ser humano. También hemos afirmado que esta obra constituye un nuevo hito en la producción artística de Omar Serra. Sostenemos esta afirmación dado que, luego de las referencias realizadas acerca de los rasgos constitutivos de esta puesta en escena, observamos que la misma reafirma tanto los postulados éticos y estéticos como filosóficos que, con total coherencia, Omar Serra ha manifestado siempre en su hacer.

Al comparar las obras de teatro -reposiciones y estrenos- que se han presentado en Rosario entre el 2017 y el 2019 (teniendo en cuenta sólo las puestas locales, sin contar las que han venido de otras ciudades o de otros países) podemos observar que la cantidad no siempre redunda en variedad. Y no nos estamos refiriendo a la calidad de los espectáculos, sabido es que la ciudad cuenta con talentosos actores y directores, pero se evidencia cierta homogeneidad en las propuestas, tanto en la poética elegida como en el registro de actuación dominante.

Entre ellos, Omar Serra, en sintonía con el Marqués de Sade, reafirmó cada sábado a la medianoche entre 2017 y 2019, desde su pequeño refugio under, que en épocas de opresión neoliberal su poética emerge más contracultural que nunca. 


\section{Q Bibliografía}

"Amícola, J. (2000). Camp y Posvanguardia, manifestaciones culturales de un siglo fenecido. Buenos Aires. Paidós.

"Bataille, G. (1988). El erotismo. Barcelona. Tusquets.

"Bordieu, P. (2002). Campo de poder, campo intelectual. Montesor. Buenos Aires.

»Butler, J. (2007). El género en disputa. El feminismo y la subversión de la identidad. Barcelona. Paidós.

»Dubatti, J. (1995). Batato Barea y el nuevo teatro argentino. Buenos Aires. Planeta.

»Dubatti, J. (2009). Concepciones de Teatro. Poéticas teatrales y bases epistemológicas. Buenos Aires. Colihue.

》Foucault, M, (1979). Microfísica del Poder. Madrid. Ed. de la Piqueta.

» Garbatzky, I. (2013). Los ochenta recienvivos. Rosario. Beatriz Viterbo Editora

" Lucena, D - G Laboureau (2016). Modo mata moda. La Plata. Edulp.

"Noy, F, (2015). Historias del under. Buenos Aires. Reservoir Books

"Ponte, D. (2015). “Aproximación a la poética teatral de Omar Serra en el contexto posdictatorial rosarino. Acerca de la construcción de dramaturgia en "La Condesa Sangrienta".Actas 69 d478_583e1fed954441f584f3d55e1ce85ca1.pdf p: 322

»Ponte, D. (2016). Acerca de la puesta en escena de Eva Perón de Copi dirigida por Omar Serra. Peronismo, camp y teatro de posdictadura en Rosario. http://www. aincrit.org/pdfs/actasaincrit2016.pdf

»Ponte, D. (2017). Reconstrucción dramatúrgica: Omar Serra reescribe Layo de Sófocles http://fido.palermo.edu/servicios_dyc/publicacionesdc/vista/detalle_articulo.php?id_libro $=637 \& i d \_a r t i c u l o=13374$

"Sade, M. (2010). Filosofía en el Tocador. Buenos Aires. Colihue.

"Serra, O. (1996). Generación Descartable. Rosario. Manuscrito inédito.

"Serra, O. (2000, 23 de septiembre). Somos los cirujas del arte, reciclamos todo el tiempo. En Diario El Ciudadano, p. 18

"Serra, O. (2001, 14 de julio). "Atravesamos la poesía con la actuación”. En Periódico El Eslabón, p. 16

"Serra, O, (2002, abril). “Date una idea”. En Revista Señales en la Hoguera, p. 12.

"Serra, O, (2011). "Cabeza de drama turco". [Entrevista inédita por Miguel Erre].

»Sontang, S. (1984). “Notas sobre lo Camp”. En Contra la interpretación y otros ensayos. Barcelona. Seix Barral. 